\title{
Potentiometric Detection of Listeria monocytogenes via a Short Antimicrobial Peptide Pair-Based Sandwich Assay
}

\author{
Enguang Lv, ${ }^{\dagger, \S}$ Jiawang Ding, ${ }^{* \dagger, \dagger(0)}$ and Wei Qin ${ }^{* \dagger, \ddagger(0)}$ \\ ${ }^{\dagger}$ Key Laboratory of Coastal Environmental Processes and Ecological Remediation and Shandong Provincial Key Laboratory of \\ Coastal Environmental Processes, Yantai Institute of Coastal Zone Research (YIC), Chinese Academy of Sciences (CAS), Yantai, \\ Shandong 264003, People's Republic of China \\ ${ }^{\ddagger}$ Laboratory for Marine Biology and Biotechnology, Qingdao National Laboratory for Marine Science and Technology, Qingdao \\ 266200, People's Republic of China \\ ${ }^{\S}$ University of the Chinese Academy of Sciences, Beijing 100049, People's Republic of China
}

Supporting Information

ABSTRACT: Peptide-based sandwich assays are promising tools in molecular detection, but may be restricted by the availability of "pairs" of affinity peptides. Herein, a new potentiometric sandwich assay for bacteria based on peptide pairs derived from an antimicrobial peptide (AMP) ligand is demonstrated. As a model, the original AMP with a welldefined structure for Listeria monocytogenes (LM) can be split into two fragments to serve as the peptide pairs for the sandwich assay. The recognition and binding of the short peptide pairs to the target can be verified by circular dichroism, flow cytometry, fluorometry, and optical microscopy. The potentiometric magnetic bead-based sandwich assay is designed by using horseradish peroxidase as a label. The enzyme can catalyze the oxidation of $3,3^{\prime}, 5,5^{\prime}$-tetramethylbenzidine with $\mathrm{H}_{2} \mathrm{O}_{2}$ to induce a potential change on a polymeric membrane ionselective electrode. Under optimal conditions, the concentration of LM can be determined potentiometrically in a linear range of $1.0 \times 10^{2}$ to $1.0 \times 10^{6} \mathrm{CFU} \mathrm{mL} \mathrm{m}^{-1}$ with a detection limit of $10 \mathrm{CFU} \mathrm{mL} \mathrm{m}^{-1}(3 \sigma)$. The proposed sensing strategy expands the applications of peptides in the field of bioassays.
S andwich assays have become a mainstay for a wide range of applications in various fields such as clinical diagnostics, environmental monitoring, and industry control. ${ }^{1}$ Such assays mainly rely on antibody and nucleic acid probes for recognition, identification, and quantification of target molecules. Antibody-based sandwich assays are the most popular platform due to their high affinities and specificities. However, the preparation of antibodies can be tedious and costly. In recent years, aptamers that can be selected in vitro and synthesized in library have been investigated as alternative bioreceptors. $^{2-4}$ Sandwich-based aptasensors have been extensively explored due to the advantages of high sensitivity and simple operation for biosensor fabrication. ${ }^{5}$

In contrast to antibodies and aptamers, peptides are intrinsically more stable in harsh environments. ${ }^{6}$ Moreover, peptides have simple and defined structures and exhibit specific and strong affinities to a variety of analytes. ${ }^{7}$ Hence, peptides have received increasing interest as recognition molecules for biosensors. ${ }^{8,9}$ Indeed, peptide-based sandwich assays, with advantages in low background signals, easy labeling, and high sensitivity, have recently been developed using various optical transduction modes. ${ }^{10,11}$ These assays require the availability of multiple distinct peptides to bind simultaneously to different sites of the analyte molecules. However, the efficient screening of multiple peptides is rather difficult and may restrict the wide applications of peptides in the sandwich format.

Antimicrobial peptides (AMPs) with a diversity of secondary structures are produced by organisms and have capabilities to kill bacteria efficiently in vitro or in vivo. ${ }^{12}$ In addition to showing the high antimicrobial potency, AMPs have also emerged as promising biorecognition probes, as they are capable of binding to the surfaces of the bacteria cells with high affinities and specificities. Several biosensor platforms for bacterial strains have been developed by using AMPs as recognition molecules. ${ }^{6,13}$ In a similar way, some shortened peptides containing less amino acids can also recognize the targets as efficiently as the original long peptides. ${ }^{14}$ Previous reports have shown that even a tetrapeptide ${ }^{15}$ can still bind to the target, which is due to the presence of the specific structure and/or amino acids. ${ }^{16}$ Therefore, short peptide pairs split from the original peptides can be a good option for the design of the peptide pair-based sandwich assay, which eliminates the selection of multiple peptides. Moreover, the short peptides may reduce the nonspecific interactions between the peptides

Received: August 21, 2018

Accepted: October 18, 2018

Published: October 18, 2018 
induced by the aromatic-aromatic ${ }^{17}$ and hydrogen bond interactions. ${ }^{18,19}$ Meanwhile, the utilization of short peptides with less positive charges could reduce the interferences from the bacteria and negatively charged species in real samples. ${ }^{20}$ However, to the best of our knowledge, short peptide pairs split from the original peptides have not been investigated and applied for biosensor design.

Herein, a short antimicrobial peptide pair-based potentiometric sandwich assay has been developed by using the antimicrobial peptide for Listeria monocytogenes (LM) as a model. LM, a Gram-positive bacterium, is one of the most virulent food-borne pathogens responsible for listeriosis. ${ }^{21}$ They widely exist in water, seafood, and sediments and can thrive with cold temperatures, high concentrations of salt, and wide $\mathrm{pHs}$ between 5.4 and 9.6. ${ }^{22,23}$ To date, a wide variety of methods including conventional as well as newly developed biosensing techniques for LM are available. ${ }^{20,24}$ Among these methods, the sandwich assays for LM have been welldeveloped using antibodies and/or aptamers as the recognition molecules. ${ }^{25,26}$ Compared with aptamer or antibody-based assays for LM, the peptide-based methods have better feasibilities due to the good stabilities of peptides. Therefore, peptide-based sandwich assays are highly desired and can be a good option for detection of LM.

In recent years, electrochemical sandwich assays have received great interest. ${ }^{1}$ Potentiometric sensors based on polymeric membrane ion-selective electrode (ISE), with attractive advantages of portability, robustness, and resistance to interference from turbidity, have been well-developed in the field of electrochemical biosensors. ${ }^{27-31}$ As promising transducers for rapid sensing and practical applications, ISEs can match the speed and low cost of sandwich immunoassays. However, the usage of ISEs for the peptide-based sandwich assays has not been investigated yet. In this work, a short peptide pair-based potentiometric sandwich assay has been designed for the first time. An original long peptide, which belongs to Leucocin $\mathrm{A}$ and possesses potent activities against Listeria strains, could be split into two fragments for the design of a short peptide pair-based sandwich assay. The capture fragment is conjugated to magnetic beads to eliminate the interference from the sample matrix. Horseradish peroxidase (HRP) is labeled to the detection fragment, for catalyzing the oxidation of $3,3^{\prime}, 5,5^{\prime}$-tetramethylbenzidine with $\mathrm{H}_{2} \mathrm{O}_{2}$, which induces the potential change on the polymeric membrane ISE. It is anticipated that the proposed bioconjugation strategy can expand the applications of peptides for bioassays.

\section{EXPERIMENTAL SECTION}

Materials and Methods. HRP-conjugated streptavidin was bought from Sangon Biotech Co., Ltd. (Shanghai, China). Magnetic beads (MBs)-conjugated streptavidin was bought from BioCanal Scientific Inc. (Shanghai, China). 3,3',5,5'Tetramethylbenzidine (TMB), high-molecular-weight poly(vinyl chloride) (PVC), o-nitrophenyl octyl ether (o-NPOE), and sodium tetraphenylborate were purchased from SigmaAldrich. All the peptides were synthesized by GL Biochem Ltd. (Shanghai, China). More details are available in the Supporting Information.

Membrane Preparation and EMF Measurements. Polymeric liquid membranes containing PVC and $o$-NPOE in a weight ratio of $1: 1$ and the cation exchanger (sodium

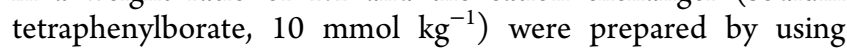

tetrahydrofuran as the solvent. The membrane electrodes were prepared as described before. ${ }^{32}$ Normally, liquid membranes contain PVC and $o-\mathrm{NPOE}$ in a weight ratio of 1:2. Herein, the decrease in the content of the plasticizer was used to control the ion diffusion coefficients and thus to maximize the observed sensitivity of the sensor. ${ }^{33}$ The inner solution of the electrode was $15 \mathrm{mM} \mathrm{NaCl}$. All electromotive force (EMF) values were measured in the following galvanic cell in a Faraday cage: $\mathrm{Ag}, \mathrm{AgCl} / 3 \mathrm{M} \mathrm{KCl} / 1.0 \mathrm{M} \mathrm{LiOAc} /$ sample solution (well-stirred, $1500 \mathrm{rpm}$ )/sensing membrane $/ 15 \mathrm{mM}$ $\mathrm{NaCl} / \mathrm{AgCl}$, Ag. A $50 \mathrm{mM} \mathrm{pH} 7.4$ phosphate buffer solution (PBS) was used as the background solution.

Potentiometric Detection of LM. First, the split peptide pairs were separately synthesized and connected with MBs and HRP via biotin-streptavidin interactions. A $2 \mu \mathrm{L}$ aliquot of HRP-conjugated streptavidin $\left(0.1 \mathrm{mg} \mathrm{mL}{ }^{-1}\right)$ was incubated with the detection fragment $\left(1.0 \times 10^{-5} \mathrm{M}, 20 \mu \mathrm{L}\right)$ for $30 \mathrm{~min}$. An $80 \mu \mathrm{L}$ aliquot of streptavidin-modified $\mathrm{MBs}\left(10 \mathrm{mg} \mathrm{mL}^{-1}\right)$ was incubated with the biotin-labeled capture fragment $(1.0 \times$ $10^{-5} \mathrm{M}, 20 \mu \mathrm{L}$ ) for $30 \mathrm{~min}$. After washing with PBS and magnetic separation, the capture-fragment-modified MBs were used for further experiments. All the incubations were carried out under gentle shaking. Second, LM at different concentrations $\left(10-1.0 \times 10^{6} \mathrm{CFU} \mathrm{mL} \mathrm{mL}^{-1}, 2.0 \mathrm{~mL}\right)$ was incubated with the two fragments for $1 \mathrm{~h}$. After incubation, separation with magnetic field, and washing twice with PBS, the final conjugates were resuspended in $0.2 \mathrm{~mL}$ of PBS. Lastly, potentiometric measurements were carried out with TMB, $\mathrm{H}_{2} \mathrm{O}_{2}$, and the final conjugates added into the background solution (PBS, $1.8 \mathrm{~mL}$ ) in order. The concentrations of TMB and $\mathrm{H}_{2} \mathrm{O}_{2}$ used were 0.1 and $0.5 \mathrm{mM}$, respectively.

Seawater Analysis. The Yantai coastal seawater samples (latitude, $37^{\circ} 29^{\prime} \mathrm{N}$; longitude, $121^{\circ} 27^{\prime} \mathrm{E}$; Yellow Sea, China) were collected. Each analyzed sample was simultaneously tested with the standard plate count method using the Listeria chromogenic medium.

\section{RESULTS AND DISCUSSION}

In this work, short peptide pairs were designed as recognition molecules of the potentiometric bioassay. The sensing principle is illustrated in Scheme 1. MBs and HRP were connected with the split peptide pairs via biotin-streptavidin interactions. In the presence of LM, the two short peptides

Scheme 1. Schematic Illustration of the Potentiometric Sandwich Assay Based on Short Antimicrobial Peptide Pairs for Detection of Listeria monocytogenes

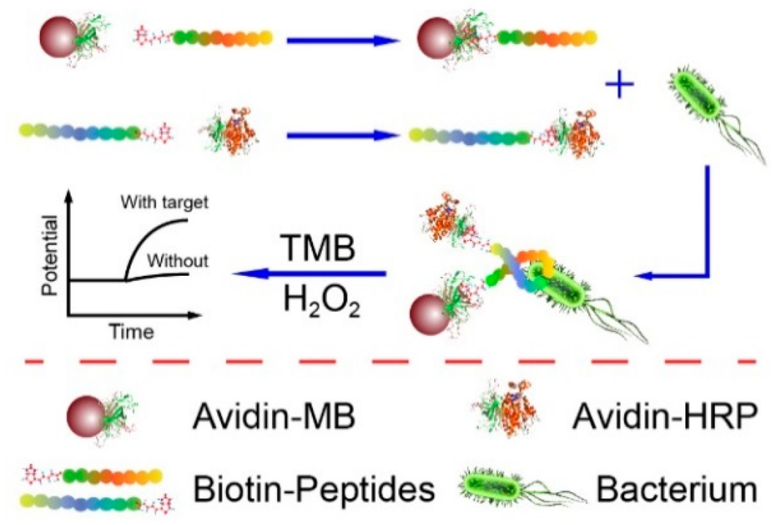


were conjugated with LM to form a sandwich complex. After magnetic separation, the conjugates were transferred to the electrochemical cell for potentiometric measurements. TMB can be efficiently oxidized in the presence of $\mathrm{H}_{2} \mathrm{O}_{2}$ and peroxidase. $^{32}$ The intermediates generated by the TMB oxidation, such as free radicals, charge transfer complexes, and diimine species, are positively charged under neutral conditions. The heterogeneous ion exchange of these cationic intermediates in the solution with the cations (e.g., $\mathrm{Na}^{+}$) in the membrane could induce a large potential response on the cation exchanger-doped polymeric liquid membrane ISE. ${ }^{32}$ Therefore, the $\mathrm{H}_{2} \mathrm{O}_{2}$-mediated oxidation of $\mathrm{TMB}$ can be detected by using the polymeric membrane ISE. The potential change, which is closely related to the amount of LM, can be used for the quantification of LM. It should be noted that $o$ phenylenediamine ${ }^{34}$ and other $\mathrm{C}$-derivatives of benzidine (such as $N, N^{\prime}, N, N^{\prime}$-tetramethylbenzidine, 3,3'-dimethoxybenzidine, and $m, m^{\prime}$-ditolylamine) can also be used as the substrates for the developed methodology. ${ }^{32}$

An original long peptide (WGEAFSAGVHRLAN) has been identified, which can recognize and capture the bacterial cells by interacting with the specific receptor on the membrane of LM to form a helical conformation. ${ }^{14}$ In this study, the original long peptide for LM, which could be split into two fragments to serve as the peptide pairs for the sandwich assay, was selected as a model. In order to improve the hydrophilic property of the short peptide pairs, asparagine and glycine were added to the ends of the original chain according to the sequence of the potent anti-listerial peptide, Leucocin A. As illustrated in Figure $1 \mathrm{~A}, \mathrm{~B}$, the split peptides were designed according to the long peptide (16 AA). To maintain the excellent recognition ability similar to the original long peptide, several conditions were taken into account. First, the main function groups (such as the carbonyl, carboxylic, amidogen, and aromatic nucleus groups), which are important for the formation of hydrogen bonds or $\pi-\pi$ bonds with protein, are essential for the specific recognition to LM. Second, the

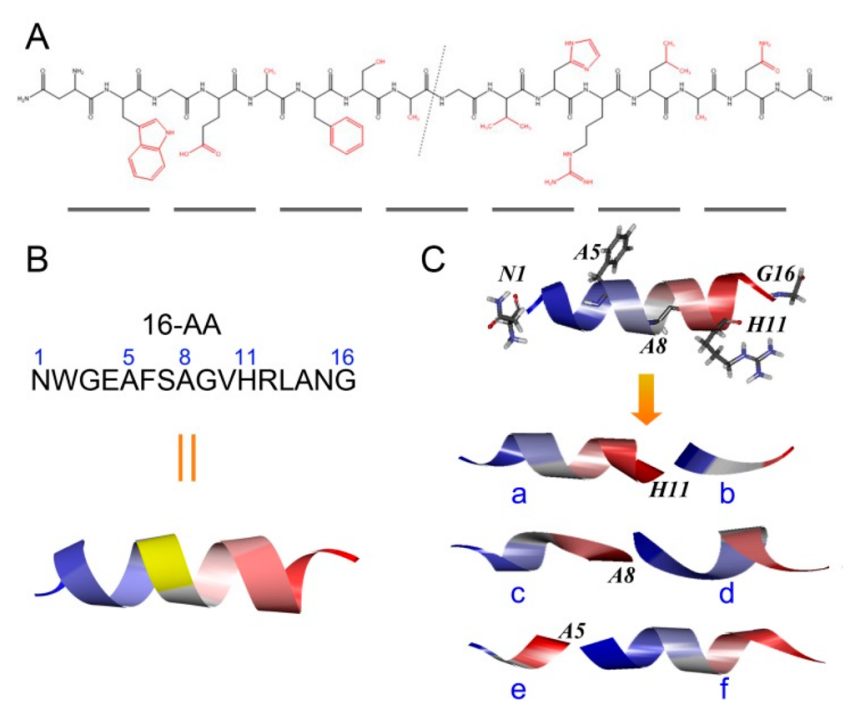

Figure 1. (A) Structural formula of the original peptide. (B) Sequence and folded structure of the original peptide. (C) Calculated folded structures of the original peptide and synthesized split peptide pairs used in this work. Herein, chains of $\mathrm{b}, \mathrm{d}$, and $\mathrm{f}$ were used as the capture fragments, and chains of a, c, and e were used as the detection fragments.
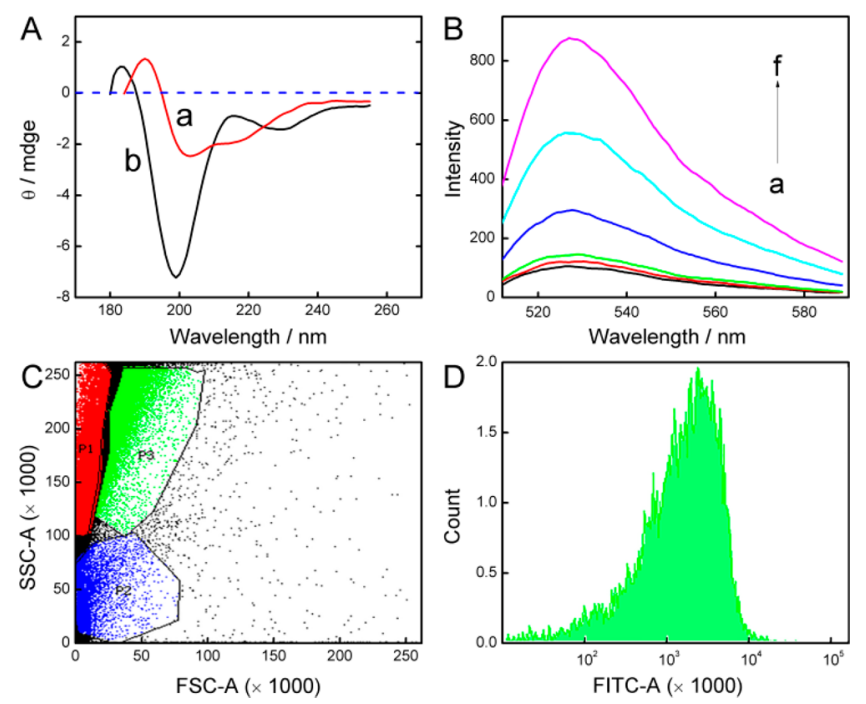

Figure 2. (A) CD spectra of peptide fragments (a, biotinNWGEAFSA; b, GVHRLANG) in $80 \%$ (2,2,2-trifluoroethanol) $\mathrm{TFE} /$ water. The concentrations of peptides were $0.2 \mathrm{mg} \mathrm{mL}^{-1}$ (ca. $200 \mu \mathrm{M}$ ). (B) Fluorescence spectra of LM at increasing concentrations: (a) 600, (b) 800 , (c) $1.0 \times 10^{3}$, (d) $2.0 \times 10^{3}$, (e) $4.0 \times 10^{3}$, and (f) $6.0 \times 10^{3} \mathrm{CFU} \mathrm{mL}^{-1}$. (C) Flow cytometry scatter plots: side scattering (SSC-A) versus forward scattering (FSC-A) of the mixture of MBs (P1), LM (P2), and the conjugates (P3). (D) Flow cytometry side scattering intensity (SSC-A) histogram of the conjugates (P3). Flow cytometric tests for MBs and LM were also carried out (see the Supporting Information). For the flow cytometric analysis, all the media volumes were $10 \mathrm{~mL}$.

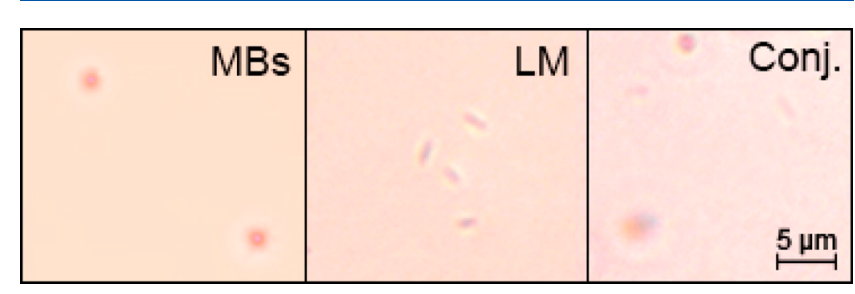

Figure 3. Optical microscopic images of MBs, LM, and the conjugates.

existence of the main amino acids (Phe, Val, and so on), which make an important contribution to the recognition, ${ }^{35}$ is essential to maintain the recognition property of the split peptide to the target. Third, both of the two split chains should contain the main amino acids and functional groups so as to maintain the recognition ability. Therefore, different cleavage sites were selected to design the short split peptide pairs.

The energy minimizations of the original peptide and the split peptides were calculated by the Discovery Studio 3.0 (Accelrys Software Inc.). As indicated in Figure 1C, for the original peptide, the helical conformation, which plays an important role in the affinity of the peptide toward LM, is formed. ${ }^{14}$ The helical structure of the peptide can be due to the distribution of the hydrophilic residues (Asn, Glu, His, Arg, and Asn) and hydrophobic residues (Trp, Phe, Val, and Leu), which occupy the opposite sides of the chain. For the peptide pairs derived from the original peptide with cleavage site A8, both of the split peptide fragments could maintain the helical structures because of the same spacial distribution of amino acids. The helical structure enables the split peptide fragments to maintain the similar recognition ability to the original long peptide. $^{14}$ However, either of the peptide pairs with the 
cleavage site of H11 or A5 lacks the essential amino acids and functional groups and thus cannot form the secondary structure. Since the $\alpha$ helix ${ }^{36,37} \beta$ sheet, ${ }^{38}$ pocket-like structure, $^{39,40}$ hydrophobicity, ${ }^{35}$ and specific amino acids (such as histidine residue ${ }^{41}$ ) of the peptides could make contributions to the target recognition, the peptides with multiple recognition sites are preferred for the proposed method.

The structural, recognition, and binding properties of the short peptide pairs with LM are the key to designing the peptide pair-based sandwich assay. Measurements were performed to establish that the short peptide pairs can be successfully integrated in a sandwich assay format. Circular dichroism (CD), as a valuable property for characterizing the structures of proteins ${ }^{42}$ and peptides ${ }^{43}$ in solution, was used to study the conformation of the synthetic short peptide pairs. As shown in Figure 2A, the CD spectra of the split peptide pairs show negative minima at about 200 and $220 \mathrm{~nm}$ and a positive band at about $190 \mathrm{~nm}$, which are similar to the characteristic peaks of the helical conformation. ${ }^{14}$ The shifts of peaks may be due to the flexibilities of the short peptide pairs, which is illustrated in the calculated folded structures of the original peptide and short peptide pairs (Figure 1C).

Fluorescence analysis was carried out for verification of the recognition and binding of the two split peptides with LM. A sandwich-structured fluorescence assay based on short peptide pairs was designed using fluorescein isothiocyanate (FITC, a derivative of fluorescein) as a fluorescent probe (Supporting Information Figure S1). As shown in Figure 2B, with increasing the concentration of LM, the fluorescence intensity can be increased, which is due to the increasing amount of the assembled conjugates.

Flow cytometric analysis also demonstrates the interactions between the short peptide pairs and LM. FITC was used to modify the peptide (Figure S1). As shown in Figure 2C, the intensities of forward scattering (FSC) and side scattering (SSC) indicate the volume differences of MBs (ca. $1 \mu \mathrm{M}$ ) and LM (ca. $1 \mu \mathrm{M} \times 2-5 \mu \mathrm{M}$ ) (Figure S2), which are in good agreement with previous reports. ${ }^{4,20}$ After incubation, MBs and LM were connected by the short peptide pairs to form the conjugates. The conjugates show an intensity distribution different from those of LM and MBs (Figure S2). Moreover, strong fluorescent intensity of the conjugates can be obtained (Figure 2D). In contrast, no fluorescence signal was observed in the absence of the short peptide pairs (Figure S2).

The inverted microscope (Zeiss, Japan) equipped with a digital camera (Qimaging, Canada) was used to observe the movement of the conjugates of MBs and the bacterial cells visually. The images and video were processed by Photoshop and Premiere Pro (Adobe Systems, Inc.), respectively. As shown in Figure 3, MBs, bacteria, and their conjugates can be resolved clearly. Compared with the bacterial cells at the same concentration, for the mixture of the cells and MBs, less free cells were observed due to the formation of conjugates of LM and MBs. Video S1 showing MBs, LM, and the conjugates can be found in the Supporting Information. As shown in the video, both the MBs and active bacteria cells can be observed. After incubation, the MBs and bacteria cells can be connected with the short split peptide pairs to form the sandwich conjugates. Interestingly, the motion of the conjugate can be observed, which indicates the conjugated LM cell is alive.

All these above results indicate that the short peptide pairs can be successfully integrated in a sandwich assay format.
While details of the mechanism of target recognition are still elusive, previous research has shown that the main amino acids (Trp, Glu, Phe, Ser, Val, Arg, Ala, and Asn) with functional groups (carbonyl, carboxylic, amidogen, and aromatic nucleus groups) play important roles in maintaining the recognition abilities of the peptides for LM. ${ }^{17-19}$ Indeed, phenylalanine and valine have been proved to be essential to maintain the recognition properties ${ }^{35}$ and could serve as the identification sites. On the other hand, several studies have shown that the proteins of the sugar transporter mannose phosphotransferase system exposed on the bacterial cell membrane could be the receptors. $^{44-46}$

In this work, potentiometric determination of LM using designed short peptide pairs as recognition molecules was carried out. The short peptides may reduce the nonspecific interactions between the cationic peptide and the negatively charged cell membrane of $\mathrm{LM}^{20}$ In order to achieve sensitive detection of LM, the experimental conditions were optimized. Considering that the cleavage site plays an important role in the formation of the secondary structure for LM recognition, short peptide pairs designed with different cleavage sites (Figure 1) were investigated. As shown in Figure 4A, the short peptide pairs synthesized according to cleavage site A8 exhibit larger potential change than the others. The possible reason is that the short chains synthesized according to cleavage sites H11 and A5 lack the essential amino acids and functional groups and thus cannot form the secondary structures efficiently. Therefore, the synthesized short peptide pairs based on cleavage site A8 were employed for subsequent experiments.

As shown in Figure 4B, the absorbance of the peptide pair solution is largely diminished after incubation with the MBs and separation with the magnetic field, which indicates that the peptide pair is successfully connected on the MBs. According to the immobilization efficiency measured by UV-vis spectroscopy, the concentration of peptide modified on the MBs was calculated to be ca. $9.0 \mu \mathrm{M}$. Since the amounts of HRP and MBs play an important role in the potentiometric detection of LM, the concentrations of HRP and MBs used in the system were then optimized. As shown in Figure 4C, the potentiometric change of the electrode increases as the amount of HRP increases due to the TMB oxidation catalyzed by HRP. A maximum can be obtained when the amount of HRP increases up to $2.0 \mu \mathrm{L}$ of $1.0 \times 10^{5} \mathrm{ng} \mathrm{mL}^{-1}$. Therefore, $2.0 \mu \mathrm{L}$ of $1.0 \times 10^{5} \mathrm{ng} \mathrm{mL}{ }^{-1} \mathrm{HRP}$ was used for further experiments. With increasing of the amount of MBs, more conjugates can be separated and thus the potential response could increase. Figure $4 \mathrm{D}$ shows that $80 \mu \mathrm{L}$ of $\mathrm{MBs}\left(10 \mathrm{mg} \mathrm{mL}^{-1}\right)$ can

Table 1. Comparison of the Analysis Times and Detection Limits for Measuring Listeria monocytogenes Using Different Methods

$\begin{array}{llcl}\quad \text { method } & \begin{array}{c}\text { analysis time } \\ (\mathrm{h})\end{array} & \begin{array}{c}\text { detection limit } \\ \left(\mathrm{CFU} \mathrm{\textrm {mL } ^ { - 1 } )}\right.\end{array} & \text { ref } \\ \begin{array}{l}\text { immunosensor based on } \\ \text { SPR }\end{array} & >2 & 2 \times 10^{6} & 48 \\ \begin{array}{c}\text { piezoelectric cantilever } \\ \text { sensor }\end{array} & 1 & 1 \times 10^{2} & 49 \\ \begin{array}{l}\text { fluorescent aptasensor } \\ \text { potentiometric } \\ \text { aptasensor }\end{array} & 2 & 20 & 50 \\ \begin{array}{c}\text { potentiometric } \\ \text { sandwich assay }\end{array} & 1 & 10 & 20 \\ \end{array}$


Table 2. Determination of Listeria monocytogenes in Spiked Coastal Seawater Samples $(n=3)$

\begin{tabular}{|c|c|c|c|c|}
\hline sample & added $\left(\mathrm{CFU} \mathrm{mL} L^{-1}\right)$ & found $\left(\mathrm{CFU} \mathrm{mL} \mathrm{m}^{-1}\right)$ & recovery (\%) & result by SPC \\
\hline seawater 1 & 0 & & & 0 \\
\hline seawater 2 & 100 & $90 \pm 20$ & 90 & $100 \pm 10$ \\
\hline seawater 3 & $5.0 \times 10^{2}$ & $(4.6 \pm 0.5) \times 10^{2}$ & 92 & $500 \pm 50$ \\
\hline seawater 4 & $1.0 \times 10^{3}$ & $(0.9 \pm 0.2) \times 10^{3}$ & 90 & $1000 \pm 70$ \\
\hline
\end{tabular}

${ }^{a}$ Average value of three determinations \pm standard deviation. ${ }^{b}$ SPC stands for the standard plate count method using the Listeria chromogenic medium
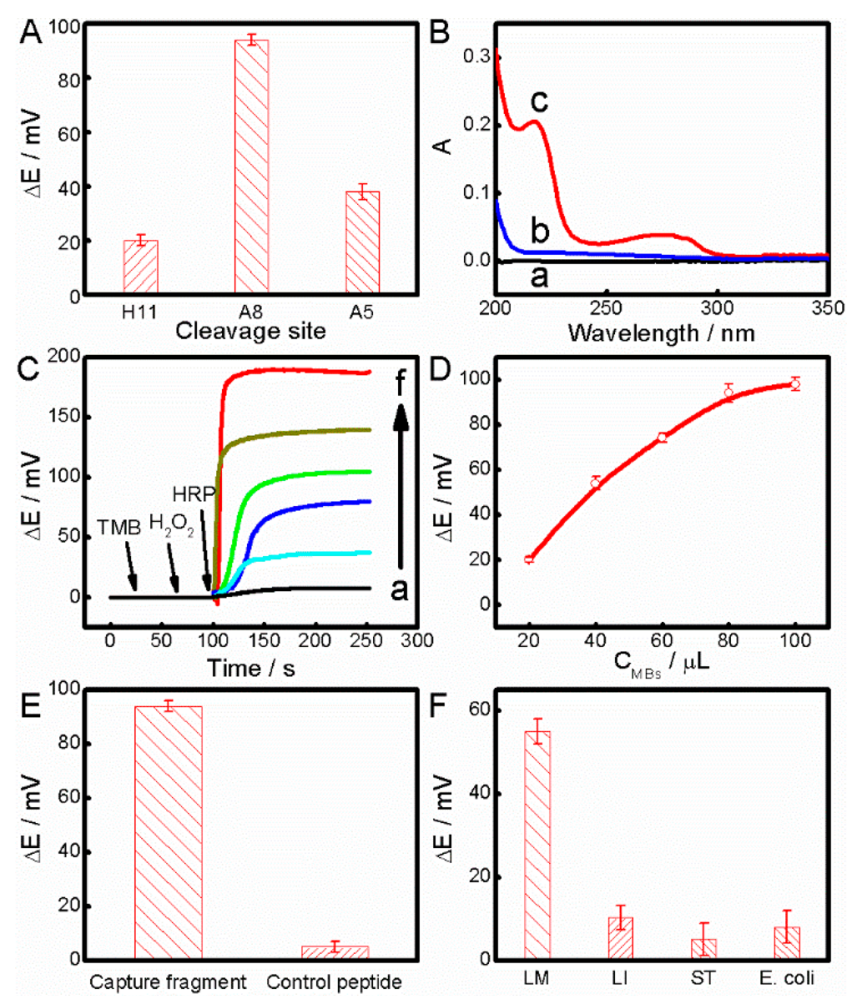

Figure 4. (A) Potential responses with short peptide pairs designed according to different cleavage sites. (B) UV-vis spectra of (a) the blank (binding buffer), (b) the peptide (capture fragment, $10^{-5} \mathrm{M}, 20$ $\mu \mathrm{L})$ after incubation with magnetic beads $(80 \mu \mathrm{L})$ for 30 min, and (c) peptide solution alone $\left(10^{-5} \mathrm{M}, 20 \mu \mathrm{L}\right)$ after incubation with binding buffer $(80 \mu \mathrm{L})$ for $30 \mathrm{~min}$. (C) Potential responses of the electrode with $2 \mu \mathrm{L}$ of (a) 1.0 , (b) 10 , (c) $1.0 \times 10^{2}$, (d) $1.0 \times 10^{3}$, (e) $1.0 \times$ $10^{4}$, and (f) $1.0 \times 10^{5} \mathrm{ng} \mathrm{mL}^{-1}$ HRP. (D) Potential responses with 2 $\mu \mathrm{L}$ of $1.0 \times 10^{5} \mathrm{ng} \mathrm{mL}^{-1} \mathrm{HRP}$ in the presence of $20-100 \mu \mathrm{L}$ of the functionalized magnetic beads. (E) Potential responses with the capture fragment and the control. (F) Potentiometric responses to

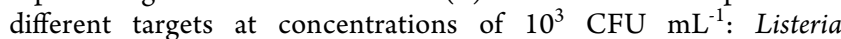
monocytogenes (LM), Listeria iuanuii (LI), Salmonella typhimurium (ST), and Escherichia coli 0157:H7 (E. coli). Unless stated otherwise, the experimental conditions are as follows: TMB, $0.1 \mathrm{mM} ; \mathrm{H}_{2} \mathrm{O}_{2}, 0.5$ $\mathrm{mM}$; peptides, $1.0 \times 10^{-5} \mathrm{M}, 20 \mu \mathrm{L}$; HRP, $1.0 \times 10^{5} \mathrm{ng} \mathrm{mL}^{-1}, 2 \mu \mathrm{L}$;

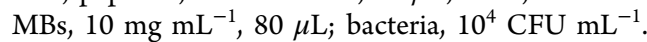

dramatically increase the potential responses due to the efficient separation of the conjugates. Thereafter, the potential response of the electrode tends to increase gradually. Thus, 80 $\mu \mathrm{L}$ of $\mathrm{MBs}$ was used for further experiments.

Control experiments using a scramble peptide as the capture fragment were carried out to validate the specificity of this method. As illustrated in Figure 4E, there is no significant signal obtained for the control peptide. The selectivity was investigated in binding of the short peptide pairs-functionalized sensor toward various bacterial species (Figure 4F). As shown
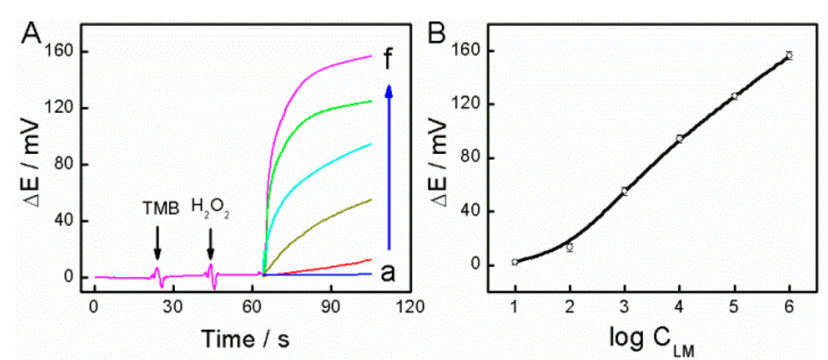

Figure 5. (A) Potential responses to $L M$ at increasing concentrations: (a) 10 , (b) $1.0 \times 10^{2}$, (c) $1.0 \times 10^{3}$, (d) $1.0 \times 10^{4}$, (e) $1.0 \times 10^{5}$, (f)

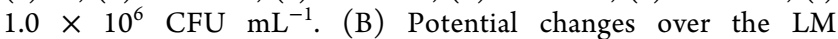
concentration range of $10^{1}-10^{6} \mathrm{CFU} \mathrm{mL} \mathrm{m}^{-1}$. Each error bar represents one standard deviation for three measurements.

in Figure 4F, other bacteria show no significant potential responses on the electrode, which is probably owing to the narrow activity spectrum of the proposed peptide. The amount of expression of specific protein also could affect the selectivity. ${ }^{47}$ Moreover, the applications of short peptides could reduce the nonspecific interactions between the positively charged peptides and the negatively charged bacterial cells.

Under optimized experiments, the potential change of the electrode increases with the increase in the amount of LM (Figure 5A). As shown in Figure 5B, the target $\mathrm{LM}$ can be detected with a concentration linear range of $1.0 \times 10^{2}$ to $1.0 \times$ $10^{6} \mathrm{CFU} \mathrm{mL} \mathrm{mL}^{-1}\left(R^{2}=0.99\right)$. The potentiometric sensing assay is able to detect the target bacterium at concentrations down to $10 \mathrm{CFU} \mathrm{mL} \mathrm{mL}^{-1}(3 \sigma)$. A comparison of the proposed potentiometric sensor and other detection methods is listed in Table 1.

To evaluate the applicability of the present potentiometric sensor, spiked coastal seawater samples were tested. The standard addition method was used to investigate the performance because the level of LM in seawater was too low to be detected. The amounts of LM obtained with this method are consistent with those found by the standard plate count method (Table 2). In this study, no filtration system was used for the sample analysis. Since the conjugates were separated from the sample solution via the magnetic field, the interferences from the seawater background could be eliminated. For complex sample matrixes, by coupling the sensor with an online filtration system, the target organisms can be preconcentrated and the interferences from ions and small molecules in the sample solutions can be eliminated. ${ }^{20}$ Even though some biological species (such as proteins and histiocytes) in the samples may affect the recognition of the peptides to LM, these interferences can be reduced by selecting peptides with high binding affinities. The proposed sandwich assay can be performed via magnetic separationbased flow-injection analysis to achieve high-throughput measurements for practical applications. ${ }^{51,52}$ 


\section{CONCLUSIONS}

In conclusion, a potentiometric sensor for LM has been developed by using short peptide pairs as recognition molecules for the first time. Such short peptide pairs can be designed by splitting the original long peptide and used as the recognition "pairs" of the sandwich assay, which expands the applications of peptides in the field of biosensors. The proposed antimicrobial peptide pair-based sandwich assay has been used for the detection of LM in seawater. Moreover, the use of magnetic beads could eliminate the background interferences from the complex matrixes by magnetic separation. This elegant approach can be extensively adopted for detection of the targets with multiple binding sites (such as bacteria and proteins), for which the specific peptides are available.

\section{ASSOCIATED CONTENT}

\section{S Supporting Information}

The Supporting Information is available free of charge on the ACS Publications website at DOI: 10.1021/acs.analchem.8b03809.

Additional information including materials, methods, and membrane preparation for potential detection, calculation of energy minimization of the peptides, circular dichroism analysis, flow cytometric analysis, fluorescence analysis and supporting figures (PDF) Video S1 showing MBs, LM, and conjugates (AVI)

\section{AUTHOR INFORMATION}

\section{Corresponding Authors}

*Tel.: +86 535 2109153. Fax: +86 535 2109000. E-mail: jwding@yic.ac.cn (J.W.D.)

*Tel.: +86 535 2109156. Fax: +86 535 2109000. E-mail: wqin@yic.ac.cn (W.Q.)

\section{ORCID}

Jiawang Ding: 0000-0002-8361-9102

Wei Qin: 0000-0002-9606-7730

Notes

The authors declare no competing financial interest.

\section{ACKNOWLEDGMENTS}

This work was financially supported by the National Natural Science Foundation of China (Grant Nos. 21575158, 21475148, and 41876108); the Strategic Priority Research Program of the Chinese Academy of Sciences (Grant No. XDA11020702); the Taishan Scholar Program of Shandong Province (Grant No. TS20081159); the National Key Research and Development Program of China (Grant No. 2016YFC1400700); and the Key Research and Development Program of Yantai (Grant No. 2018ZHGY053). We also acknowledge Dr. Fei Li from Yantai Institute of Coastal Zone Research, who provided kind help for the molecular docking.

\section{REFERENCES}

(1) Shen, J. W.; Li, Y. B.; Gu, H. S.; Xia, F.; Zuo, X. L. Chem. Rev. 2014, 114, 7631-7677.

(2) Iliuk, A. B.; Hu, L.; Tao, W. A. Anal. Chem. 2011, 83, 44404452.

(3) Tang, D.; Tang, J.; Li, Q.; Su, B.; Chen, G. Anal. Chem. 2011, 83, $7255-7259$.

(4) Ding, J. W.; Gu, Y.; Li, F.; Zhang, H. X.; Qin, W. Anal. Chem. 2015, 87, 6465-6469.
(5) Sassolas, A.; Blum, L. J.; Leca-Bouvier, B. D. Electroanalysis 2009, 21, 1237-1250.

(6) Etayash, H.; Jiang, K.; Thundat, T.; Kaur, K. Anal. Chem. 2014, $86,1693-1700$.

(7) Pavan, S.; Berti, F. Anal. Bioanal. Chem. 2012, 402, 3055-3070.

(8) Liu, Q.; Wang, J.; Boyd, B. J. Talanta 2015, 136, 114-127.

(9) Papp, S.; Jágerszki, G.; Gyurcsanyi, R. E. Angew. Chem., Int. Ed. 2018, 57, 4752-4755.

(10) Wang, H. J.; Yuan, Y. L.; Chai, Y. Q.; Yuan, R. Small 2015, 11, 3703-3709.

(11) Xiong, J.; Wang, W.; Fu, Z. Microchim. Acta 2017, 184, 41974202.

(12) Silva, O. N.; de la Fuente-Núñez, C.; Haney, E. F.; Fensterseifer, I. C. M.; Ribeiro, S. M.; Porto, W. F.; Brown, P.; Faria-Junior, C.; Rezende, T. M. B.; Moreno, S. E.; Lu, T. K.; Hancock, R. E. W.; Franco, O. L. Sci. Rep. 2016, 6, 35465.

(13) Chen, H. Y.; Liu, C. C.; Chen, D.; Madrid, K.; Peng, S. W.; Dong, X. Y.; Zhang, M.; Gu, Y. Q. Mol. Pharmaceutics 2015, 12, $2505-2516$.

(14) Azmi, S.; Jiang, K.; Stiles, M.; Thundat, T.; Kaur, K. ACS Comb. Sci. 2015, 17, 156-163.

(15) Reiss, Y.; Stradley, S. J.; Gierasch, L. M.; Brown, M. S.; Goldstein, J. L. Proc. Natl. Acad. Sci. U. S. A. 1991, 88, 732-736.

(16) Zasloff, M. Nature 2002, 415, 389-395.

(17) Burley, S.; Petsko, G. Science 1985, 229, 23-28.

(18) Klotz, I. M.; Franzen, J. S. J. Am. Chem. Soc. 1962, 84, 34613466.

(19) Murphy, K. P.; Xie, D.; Garcia, K. C.; Amzel, L. M.; Freire, E. Proteins: Struct., Funct., Genet. 1993, 15, 113-120.

(20) Ding, J. W.; Lei, J. H.; Ma, X.; Gong, J.; Qin, W. Anal. Chem. 2014, 86, 9412-9416.

(21) Farber, J. M.; Peterkin, P. I. Microbiol. Rev. 1991, 55, 476-511.

(22) Buchanan, R. L.; Phillips, J. G. J. Food Prot. 1990, 53, 370-376.

(23) Lu, X. N.; Rasco, B. A.; Kang, D. H.; Jabal, J. M. F.; Aston, D. E.; Konkel, M. E. Anal. Chem. 2011, 83, 4137-4146.

(24) Välimaa, A.-L.; Tilsala-Timisjärvi, A.; Virtanen, E. Food Control 2015, 55, 103-114.

(25) Cheng, C.; Peng, Y.; Bai, J.; Zhang, X.; Liu, Y.; Fan, X.; Ning, B.; Gao, Z. Sens. Actuators, B 2014, 190, 900-906.

(26) Cimaglia, F.; De Lorenzis, E.; Mezzolla, V.; Rossi, F.; Poltronieri, P. IEEE Sens. J. 2016, 16, 7045-7052.

(27) Bakker, E.; Pretsch, E. Angew. Chem., Int. Ed. 2007, 46, 56605668.

(28) Bobacka, J.; Ivaska, A.; Lewenstam, A. Chem. Rev. 2008, 108, $329-351$

(29) Ding, J. W.; Chen, Y.; Wang, X. W.; Qin, W. Anal. Chem. 2012, 84, 2055-2061.

(30) Bakker, E. Anal. Chem. 2016, 88, 395-413.

(31) Jagerszki, G.; Takacs, A.; Bitter, I.; Gyurcsanyi, R. E. Angew. Chem., Int. Ed. 2011, 50, 1656-1659.

(32) Wang, X. W.; Yang, Y. G.; Li, L.; Sun, M. S.; Yin, H. G.; Qin, W. Anal. Chem. 2014, 86, 4416-4422.

(33) Fu, B.; Bakker, E.; Yun, J. H.; Yang, V. C.; Meyerhoff, M. E. Anal. Chem. 1994, 66, 2250-2259.

(34) Wang, X. W.; Qin, W. Chem. - Eur. J. 2013, 19, 9979-9986.

(35) Fregeau Gallagher, N. L.; Sailer, M.; Niemczura, W. P.; Nakashima, T. T.; Stiles, M. E.; Vederas, J. C. Biochemistry 1997, 36, 15062-15072.

(36) Sato, H.; Feix, J. B. Biochim. Biophys. Acta, Biomembr. 2006, $1758,1245-1256$.

(37) Puiu, M.; Idili, A.; Moscone, D.; Ricci, F.; Bala, C. Chem. Commun. 2014, 50, 8962-8965.

(38) Hirakura, Y.; Kobayashi, S.; Matsuzaki, K. Biochim. Biophys. Acta, Biomembr. 2002, 1562, 32-36.

(39) Wu, J.; Zou, Y.; Li, C.; Sicking, W.; Piantanida, I.; Yi, T.; Schmuck, C. J. Am. Chem. Soc. 2012, 134, 1958-1961.

(40) Rodriguez-Vazquez, N.; Amorin, M.; Alfonso, I.; Granja, J. R. Angew. Chem., Int. Ed. 2016, 55, 4504-4508. 
(41) Wang, P.; Liu, L.; Zhou, P.; Wu, W.; Wu, J.; Liu, W.; Tang, Y. Biosens. Bioelectron. 2015, 72, 80-86.

(42) Kelly, S. M.; Jess, T. J.; Price, N. C. Biochim. Biophys. Acta, Proteins Proteomics 2005, 1751, 119-139.

(43) Sonnichsen, F. D.; Van Eyk, J. E.; Hodges, R. S.; Sykes, B. D. Biochemistry 1992, 31, 8790-8798.

(44) Kjos, M.; Borrero, J.; Opsata, M.; Birri, D. J.; Holo, H.; Cintas, L. M.; Snipen, L.; Hernandez, P. E.; Nes, I. F.; Diep, D. B. Microbiology 2011, 157, 3256-3267.

(45) Diep, D. B.; Skaugen, M.; Salehian, Z.; Holo, H.; Nes, I. F. Proc. Natl. Acad. Sci. U. S. A. 2007, 104, 2384-2389.

(46) Kjos, M.; Salehian, Z.; Nes, I. F.; Diep, D. B. J. Bacteriol. 2010, 192, 5906-5913.

(47) Etayash, H.; Norman, L.; Thundat, T.; Kaur, K. Langmuir 2013, 29, 4048-4056.

(48) Wang, Y.; Knoll, W.; Dostalek, J. Anal. Chem. 2012, 84, 83458350.

(49) Sharma, H.; Mutharasan, R. Biosens. Bioelectron. 2013, 45, 158162.

(50) Lee, S. H.; Ahn, J. Y.; Lee, K. A.; Um, H. J.; Sekhon, S. S.; Sun Park, T.; Min, J.; Kim, Y. H. Biosens. Bioelectron. 2015, 68, 272-280.

(51) Biscay, J.; Begoña González García, M.; García, A. C. Electroanalysis 2014, 26, 1893-1900.

(52) Lei, J. H.; Ding, J. W.; Qin, W. Anal. Methods 2015, 7, 825829. 